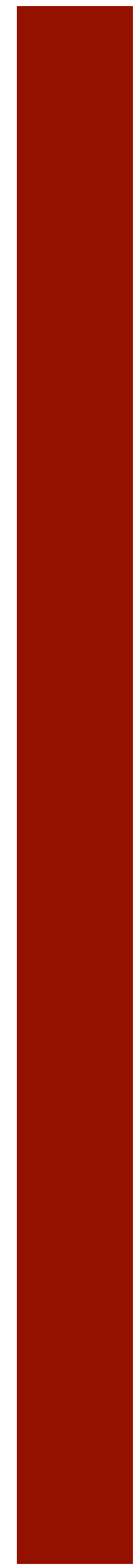

Entrevista 


\section{Eros Carvalho: \\ diálogos interdisciplinares urgentes}

DOI: 10.12957/ek.2021.56627

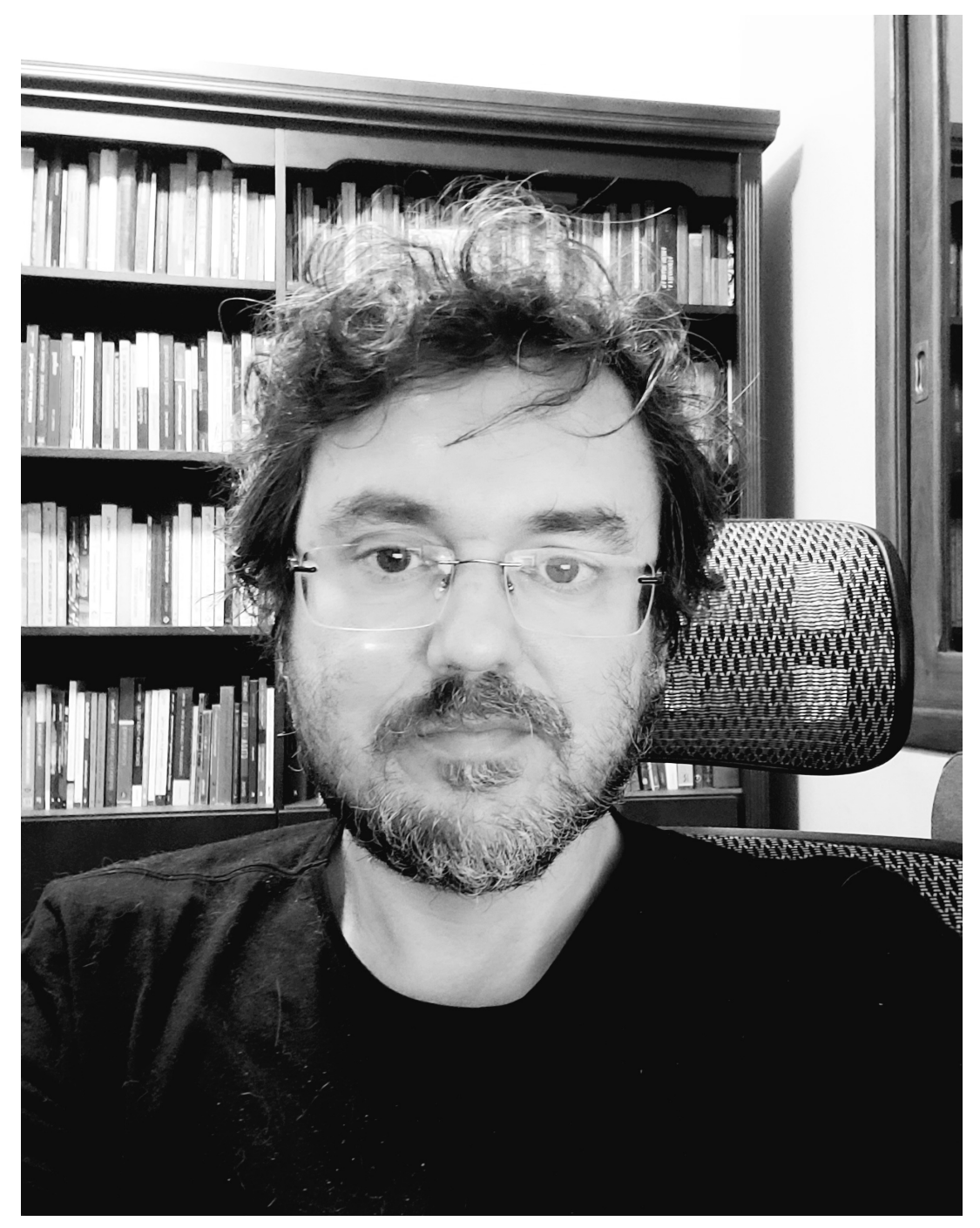

\section{Entrevista com Eros Moreira de Carvalho}

por Christiane Costa de Matos Fernandes, Deborah Moreira Guimarães,

Fábio Candido dos Santos e Taciane Alves da Silva ${ }^{1}$

\footnotetext{
${ }^{1}$ Esta entrevista foi elaborada por Christiane Costa de Matos Fernandes, Deborah Moreira Guimarães, Fábio Candido dos Santos e Taciane Alves da Silva. As perguntas foram enviadas por e-mail ao professor e pesquisador Dr. Eros Carvalho, que as respondeu por escrito. Agradecemos ao Prof. Eros Carvalho não apenas a disposição em realizar a entrevista como também a gentileza e a solicitude para com o corpo editorial da Revista Ekstasis.
} 


\section{Apresentação}

Em nossa terceira entrevista, temos o prazer e a alegria de trazer uma conversa interdisciplinar com o Prof. Dr. Eros Carvalho. Eros Moreira de Carvalho doutorou-se pela UFMG em 2007, onde defendeu a tese intitulada "Em Defesa da Justificação Perceptiva: Desmistificando o Mito do Dado”. Atualmente é professor associado do departamento de filosofia da Universidade Federal do Rio Grande do Sul (UFRGS) e bolsista de Produtividade em Pesquisa do CNPq. Entre março de 2017 e fevereiro de 2018 realizou visita acadêmica na University of Edinburgh pelo programa da CAPES de Estágio Sênior no Exterior. Além disso, também é membro do Enactive Cognition and Narrative Research Group (University of Wollongong, Australia).

Com experiência nas áreas de epistemologia, filosofia geral da ciência e filosofia das ciências cognitivas, suas pesquisas lidam principalmente com questões relacionadas à percepção, ao conhecimento obtido por inferência indutiva e à filosofia das ciências cognitivas. Eros Carvalho considera a interlocução com outras áreas do saber fundamental para a reflexão filosófica. A atenção e diálogo com a literatura empírica é especialmente saliente nos seus trabalhos sobre a percepção. Também defende mais diálogo entre as diferentes tradições filosóficas. Nesse sentido, tem nutrido especial interesse pela investigação fenomenológica sobre a percepção.

Atualmente tem pesquisado sobre a relação entre percepção e ação a partir da concepção ecológica e enativa da mente ${ }^{2}$. No projeto de pesquisa "Conhecimento como uma habilidade", defende a hipótese de trabalho, apoiada na psicologia ecológica, de que habilidades práticas, em especial, as habilidades de discriminação perceptiva, são incorporadas, situadas e dependentes do ambiente. Suas participações no debate público reivindicam o diálogo entre as ciências e as humanidades, bem como a necessidade de repensarmos o arranjo institucional da ciência inserindo a sociedade civil ao longo do processo de produção do conhecimento.

\footnotetext{
${ }^{2}$ Veja, por exemplo, os artigos "An Ecological Approach to Disjunctivism", publicado na Synthese, disponível em https://link.springer.com/article/10.1007/s11229-019-02253-2, e "Affordances Sociais e a Tese da Mente Socialmente Estendida", disponível em: https://www.academia.edu/39728821/Affordances_Sociais_e_a_Tese_da_Mente_Socialmente_Estendida
} 


\section{Entrevista}

1. No artigo As humanidades $e$ o uso adequado das ciências ${ }^{3}$ você afirma a necessidade urgente de estabelecermos diálogos entre as humanidades e a ciência. Tendo em vista a atual pandemia de Covid-19, que colocou o mundo todo em uma situação sem precedentes, e, consequentemente, a necessidade urgente de pensar políticas públicas capazes de solucionar os problemas sociais agravados pela crise global, a ciência ganhou status de "verdade inquestionável", sendo instrumentalizada, portanto, conforme os interesses particulares dos diversos líderes que ganharam destaque no combate aos efeitos danosos dessa "nova realidade". Conforme o artigo, esses usos práticos da ciência carecem, muitas vezes, de elucidação no que diz respeito ao próprio processo de produção do conhecimento científico. "Uma vez que as observações e as experimentações realizadas são limitadas e o domínio dos fenômenos investigados é potencialmente infinito", como pensar a validação dos modelos científicos se estes representam apenas simplificações e abstrações da realidade.

Em primeiro lugar, gostaria de contextualizar um pouco o fenômeno da autoridade da ciência. É verdade que se a ciência não gozasse de uma relativa autoridade, tentativas de politizá-la e instrumentalizá-la seriam raras. Se há autoridades públicas, no Brasil ou em qualquer parte do mundo, que fazem um apelo meramente retórico à ciência em suas tomadas de decisões, é porque reconhecem que ela tem autoridade junto à sociedade civil. As autoridades procuram, assim, dar credibilidade às suas decisões e eximir-se de responsabilidade caso as consequências sejam infelizes. Eu não tenho dados para afirmar que isso tem ocorrido e com que frequência, mas é natural que levantemos suspeitas nos casos em que não há qualquer transparência no processo pelo qual a autoridade pública é informada pela ciência.

\footnotetext{
${ }^{3}$ Cf. CARVAlHO, Eros. As humanidades e o uso adequado das ciências. Acesso disponível em: https://estadodaarte.estadao.com.br/humanidades-ciencias-eros/. Estadão. Estado da Arte: revista de cultura, artes e ideias. 06 de maio de 2020.
} 
Agora, é fato que a ciência ganhou status de "verdade inquestionável”? Não me parece que este seja o caso em nenhum lugar do mundo e muito menos no Brasil. Este ano foi publicada uma pesquisa sobre a percepção da confiabilidade da ciência em diversos países ${ }^{4} .20$ países foram analisados, entre eles o Brasil. A boa notícia é que comparativamente a outras instituições, como os governos e a mídia, a ciência é vista como mais confiável. Em países como a Índia, a Suécia, a Austrália e a Holanda, apenas uma parcela pequena da população não confia muito ou não confia absolutamente na ciência. A má notícia é que na média a maior parte das populações dos países investigados têm alguma, mas não muita, confiança na ciência. O Brasil, a Malásia e a Tailândia são os que menos confiam na ciência. No Brasil, apenas $23 \%$ da população confia muito na ciência, 36\% tem alguma confiança e outros 36\% não confia muito ou não confia absolutamente na ciência.

No início da pandemia do novo coronavírus no Brasil, confesso que eu mesmo fiquei relativamente impressionado, como transparece no meu texto publicado no Estado da Arte, com os apelos à ciência para as tomadas de decisões, especialmente por parte dos governadores e prefeitos. Fez-me pensar que a ciência gozava em nossa sociedade de uma autoridade muito maior do que eu inicialmente imaginava. Posso estar equivocado, mas a minha impressão é que esses apelos são cada vez menos frequentes ou no mínimo menos compromissados, o que é, infelizmente, mais coerente com a confiança que a nossa população deposita na ciência, segundo a pesquisa mencionada. Conjecturo que as nossas autoridades públicas mais ou menos copiaram no início as respostas das autoridades mundo afora, onde a ciência é vista como muito mais confiável do que aqui, e foram paulatinamente ajustando o seu comprometimento com a ciência em conformidade com o que perceberam ser as reais convicções e exigências das populações sob suas responsabilidades. Também não podemos negligenciar as fortes pressões dos grupos econômicos prejudicados com as medidas de distanciamento social. Contudo, mesmo fazendo esse desconto, acho que hoje estamos em uma situação pior no que diz respeito

\footnotetext{
${ }^{4}$ Veja aqui uma matéria da Folha sobre a pesquisa: https://www1.folha.uol.com.br/ciencia/2020/09/brasileiros-sao-os-que-menos-confiam-em-cientistasindica-estudo-de-centro-americano.shtml O estudo completo está disponível em: https://www.pewresearch.org/science/2020/09/29/science-andscientists-held-in-high-esteem-across-global-publics/
} 
a tomadas de decisões com base na ciência do que no início dessa crise sanitária. Considere, por exemplo, o crescente ceticismo em relação às vacinas ${ }^{5}$. Temo que a participação de autoridades públicas em movimentos antivacinas irá impactar ainda mais no curto e médio prazo a nossa débil confiança na ciência, com consequências deletérias para todos nós.

Achei importante fazer essa contextualização pois no Brasil não acho que corremos nenhum risco sério de malefícios por excesso de confiança na ciência, mas estamos sim amargando muitas mazelas por excesso de desconfiança da ciência.

Respondendo agora à pergunta, de fato, a ciência trabalha com modelos que são simplificações ou abstrações da realidade. No entanto, não vejo isso como um grave problema. Dados os nossos recursos cognitivos limitados e finitos, é o que está ao nosso alcance fazer para obter conhecimento da realidade. Não temos condições de abarcar todos os detalhes da realidade ao mesmo tempo. Sem simplificações, a própria testagem torna-se difícil, pois não conseguimos controlar uma quantidade muito grande ou indefinida de variáveis para determinar os efeitos de uma variável em particular que queremos investigar. Ademais, um modelo que não abstraísse mas incorporasse todos os aspectos da realidade investigada seria inútil. A comparação com mapas pode nos ajudar a entender por quê. Um mapa com as dimensões do terreno representado não só seria impraticável, como seria dispensável, pois qualquer operação sobre ele, uma medição, por exemplo, não seria muito diferente da operação equivalente sobre o terreno. Nesse caso, seria melhor usar então o próprio terreno como "mapa" de si mesmo.

Feitas essas ressalvas, é claro que temos de reconhecer as dificuldades, sobretudo epistemológicas, que a modelagem traz. A primeira delas é evitar a tentação de confundir o modelo com a realidade. Essa tentação pode nos levar a reificar um modelo que não é mais atualizado ou modificado para dar conta de observações ou predições que entram em tensão ou contradição com ele. Uma vez reificado, alega-se que o erro está nas observações ou predições ou ainda que há causas desconhecidas que uma vez descortinadas nos ajudarão a entender essas observações ou predições aparentemente contraditórias com o modelo. Pode ser que esse seja o caso algumas vezes, mas dificilmente sempre. Para contornar a dificuldade de reificação, eu particularmente penso

\footnotetext{
${ }^{5}$ Veja esta pesquisa recente sobre o tema, "Natural Stings: Selling Distrust About Vaccines on Brazilian YouTube", disponível em: https://www.frontiersin.org/articles/10.3389/fcomm.2020.577941/full
} 
que é melhor, ainda que controverso, adotar de partida a compreensão de modelos como ferramentas que nos auxiliam a lidar e a interagir com a realidade. Como ferramentas, os modelos podem ser melhores ou piores, e podem e devem ser melhorados e aperfeiçoados, mas não podem ser confundidos com a realidade que visamos entender com o auxílio dos modelos.

Um modelo que parece ter sido reificado, pelo menos em algumas áreas da economia, é o modelo que supõe que a agência racional equivale à agência que maximiza a utilidade. Embora esse modelo possa ser bastante útil, como ferramenta, em alguns contextos bem particulares, em que fatores socioculturais estão atenuados, ele é inadequado para compreender a ação racional em geral. Trata-se de um modelo que entra em tensão com a compreensão da ação racional que obtivemos nas últimas décadas de investigação filosófica, antropológica, sociológica e histórica.

Outra dificuldade é a distorção. Modelos podem envolver suposições muito equivocadas sobre a realidade. É o que acontece com o modelo econômico que acabamos de mencionar. Além de reificado, ele distorce a nossa compreensão da agência racional ao acentuar um único fator, entre vários outros conhecidos, como constitutivo da agência racional. O modelo que ignora a influência do ambiente físico e social sobre a ontogênese do cérebro também gera graves distorções, é o modelo, como aponta Helen Longino ${ }^{6}$, que leva alguém a supor que há tal coisa como um cérebro naturalmente masculino e um feminino. As distorções devem ser combatidas, mas também não podemos nos tornar sanguinários em relação a elas. Em sentido estrito, toda simplificação envolve uma distorção. Mas nem por isso vamos rejeitar todos os modelos. As distorções devem ser encaradas como uma questão de grau. Muitos modelos, ainda que contenham distorções substantivas conhecidas, podem ser úteis em determinados contextos e situações.

Por fim, a aplicação de modelos sempre encerra um elemento de incerteza. Fora do ambiente controlado dos laboratórios, podem intervir forças inesperadas ou desconhecidas, gerando resultados não previstos. Em casos assim, é preciso ponderar se o modelo precisa ser atualizado ou se essa interferência foi casual e, portanto, não precisa ser incorporada no modelo. Não há algoritmo para esta decisão. Espera-se que o bom senso e a perícia do cientista sejam suficientes para que as decisões a este respeito sejam

\footnotetext{
${ }^{6}$ Veja LONGINO, Helen. Science as Social Knowledge. New Jersey: Princeton University Press, 1990.
} 
majoritariamente fecundas. No fundo, aperfeiçoamos modelos como aperfeiçoamos ferramentas, usando e aparando arestas diligentemente.

2. Ainda sobre o seu artigo As humanidades e o uso adequado das ciências, gostaríamos de saber como articular valores sociais e morais ao processo de tomada de decisões científicas no que diz respeito à aceitação ou à recusa de teorias científicas, sejam estas falsas ou verdadeiras. Noutras palavras, em meio ao processo atual cada vez maior de dissociação entre o conhecimento científico e as humanidades, como assegurar no contexto brasileiro atual o uso adequado $e$ ponderado da ciência em sua aplicação prática no agravamento dos problemas sociais, uma vez que somente as humanidades são capazes de responder "como as ciências podem e devem informar e assessorar governos na elaboração de políticas públicas".

Um dos caminhos para assegurar o uso adequado e ponderado da ciência na formulação de políticas públicas é a institucionalização. Até o início do século passado, os governos nacionais na sua maioria estabeleciam comitês científicos para consulta apenas em situações de calamidade, como em uma guerra ou em uma pandemia. Mas desde o final da Segunda Guerra Mundial, boa parte dos estados nacionais passou a instituir mecanismos regulares e institucionalizados de consulta científica. O sucesso prático e tecnológico da ciência tornou-a uma ferramenta indispensável para os governos. No caso do Brasil, instituições como o IBGE, o INPA e a EMPRAPA, para citar apenas algumas, criadas respectivamente nas décadas de 30, 50 e 70 do século passado, cumprem um papel fundamental no fornecimento de informações técnicas e científicas para a formulação de políticas públicas. É impensável que um governo moderno possa prover bem-estar à sua população sem o apoio de instituições deste tipo. Quando um governo ataca alguma dessas instituições, deveríamos ficar muito preocupados, pois ele está minando a própria capacidade do Estado de prover serviços sociais.

A existência destas instituições de pesquisa e levantamento de dados técnicos não é, no entanto, suficiente para assegurar o bom uso do conhecimento científico na formulação de políticas públicas. É preciso que haja também um processo formal de assessoramento técnico e científico que preveja os modos pelos quais as políticas públicas 
serão alimentadas por informação técnica e científica e que possam ser publicamente auditados. Em resumo, precisamos de mais institucionalização e transparência no uso do conhecimento científico. Creio que há muito ainda por se fazer nessa área. Em uma pesquisa de 2018 sobre o uso da ciência na formulação de políticas públicas em vários Ministérios, as autoras constataram que "o recurso ao conhecimento científico no cotidiano dos gestores não era de exigência institucional" e que "os ministérios não oferecem acesso ao portal de periódicos da Coordenação de Aperfeiçoamento de Pessoal de Nível Superior (Capes) aos seus técnicos”, revelando assim uma presença ainda titubeante do conhecimento científico nas rotinas dos Ministérios.

Contudo, a institucionalização desse processo não é tarefa fácil. Em parte, ela envolve a própria legislação sobre políticas públicas. E temos aí questões difíceis e clássicas que vão até a filosofia política: como dar voz à ciência na formulação de políticas públicas sem que isso comprometa, pelo menos nos regimes democráticos, a soberania popular? O curioso é que a própria questão, "como institucionalizar o uso da ciência na formulação de políticas públicas em regimes democráticos?”, se auto refere, pois ao mesmo tempo em que, nos regimes democráticos, ela precisa ser encaminhada e conduzida pelos órgãos representativos competentes, ela carece também das humanidades para ser respondida adequadamente. A concepção e o aperfeiçoamento deste processo de institucionalização podem e devem, a meu ver, ser auxiliados pelas humanidades. Precisamos sobretudo da ciência das políticas públicas, mas também da história, da sociologia e da filosofia para oferecer um desenho adequado da legislação sobre políticas públicas que dê e assegure a devida voz ao conhecimento científico sem, ao mesmo tempo, anular a soberania popular. É difícil imaginar que se possa dar uma solução adequada para esse problema sem conhecer a história do assessoramento científico, saber o que deu e o que não deu certo em casos passados, e sem enfrentar a questão difícil de filosofia política que ela encerra.

\section{Em um texto publicado em 21 de maio no Jornal da Universidade da UFRGS, intitulado "Por que confiar na ciência?"8 você argumenta a favor da importância da}

\footnotetext{
${ }^{7}$ Veja CARNEIRO, Maria J. T. \& Sandroni, Laila T. "Ciência e política pública na perspectiva dos gestores: clivagens e confluências". Revista Sociedade e Estado, v. 33, n. 1, 2018, p. 41-61.

${ }^{8}$ Disponível em: https://www.ufrgs.br/jornal/por-que-confiar-na-ciencial
} 
construção de laços de confiança a partir da inserção e da participação da sociedade civil ao longo do processo de produção do conhecimento. Esse movimento, ainda conforme o texto, é necessário tendo em vista a produção de dissenso acerca dos resultados científicos e também ao ataque à idoneidade de especialistas por grupos econômicos e políticos. A questão é, portanto, como você pensa a realização desses laços de confiança no Brasil em um contexto extremamente complexo e contraditório, no qual, ao mesmo tempo em que a universidade pública realiza mais de $95 \%$ da produção científica no Brasil, ${ }^{9}$ a sociedade civil tem acesso às informações científicas predominantemente por meio de plataformas virtuais, sendo que, nessas plataformas, os modos sérios e comprometidos de divulgações científicas são subjugados - ora pela manipulação dos algoritmos, ora pela divulgação em rede de pessoas que ganharam confiabilidade da sociedade civil - em favor do radicalismo conspiratório baseado no anticientificismo e na desacreditação da universidade?

A construção de espaços para a participação da sociedade civil tanto na produção do conhecimento científico quanto na formulação das políticas públicas é algo que precisa avançar e que, novamente, passa pelo aprofundamento da institucionalização dos processos participativos. Em 2014, a ex-presidenta Dilma Rousseff publicou um decreto que instituía a Política Nacional de Participação Social ${ }^{10}$. Basicamente, o decreto organizava conselhos, instâncias e procedimentos para a participação popular na formulação de políticas públicas em todas as áreas, como saúde e educação, e nas diferentes esferas do governo, municipal, estadual e federal. O decreto foi logo em seguida derrubado pelo Congresso sob a alegação de que ele invadia prerrogativas do legislativo ${ }^{11}$. Na mídia, falou-se muito que o decreto era "autoritário". Desde então, tramita no Congresso um projeto de lei ${ }^{12}$ que retoma os pontos centrais do decreto da

\footnotetext{
9 Cf:: https://www.unifesp.br/noticias-anteriores/item/3799-universidades-publicas-realizam-mais-de-95da-ciencia-no-brasil

${ }^{10}$ Veja aqui o decreto http://www.planalto.gov.br/ccivil 03/ ato2011-2014/2014/decreto/d8243.htm

${ }^{11}$ Veja aqui notícia da Câmara sobre o tema: https://www.camara.leg.br/noticias/443908-deputados-derrubam-decreto-dos-conselhos-populares/

${ }^{12}$ Veja aqui notícia sobre o projeto de Lei 8048/14:
} 
Dilma. No entanto, não parece que o Congresso o encare como matéria urgente. Já se passaram seis anos e o projeto tramita lentamente pelas diversas instâncias e comissões do congresso ${ }^{13}$. Sem pressão da própria sociedade civil organizada, acho difícil que esse projeto avance. Mas sem dúvida a institucionalização da participação da sociedade civil na formulação de políticas públicas é um dos caminhos para que a sociedade civil influencie, fazendo valer os seus interesses, se identifique com e passe a ter mais confiança nas políticas públicas que direta ou indiretamente irão lhe afetar.

Outras iniciativas paralelas e mesmo entrelaçadas com esta que acabo de mencionar tem a ver com a participação popular na própria produção do conhecimento científico. É importante frisar que não estou advogando ou falando de ciência feita por amadores. Defensores da terra plana podem achar que fazem ciência ao realizar experimentos caseiros com giroscópios ${ }^{14}$, mas não chegam nem perto de um simulacro do empreendimento científico. Não têm um programa de pesquisa, nem um sistema de autocorreção como o que é possibilitado pela replicação de experimentos, publicação de resultados e revisão por pares. Há uma dificuldade em reconhecer a relevância e a factibilidade da participação da sociedade civil na produção do conhecimento porque este último é muito técnico e especializado e também porque imaginamos logo de cara alguma situação envolvendo ciência básica. Uma pesquisa sobre as interações químicas dos neurotransmissores ou uma pesquisa sobre forças nucleares não parece poder se beneficiar da interlocução com leigos que não entendem nada do assunto.

Mas a situação muda completamente de figura quando pensamos na produção de conhecimento científico que será aplicado em áreas que afetarão diretamente certas comunidades ou populações. Aqui podemos pensar em dois tipos de situação. Considere, primeiro, a pesquisa sobre agricultura sustentável, manejo florestal ou manejo de rebanho. Esses são casos em que o conhecimento tradicional das populações que já

https://www.camara.leg.br/noticias/493862-comissao-aprova-projeto-que-retoma-criacao-de-conselhosde-consulta-popular/

${ }^{13}$ Acompanhe aqui a tramitação do projeto: https://www.camara.leg.br/proposicoesWeb/fichadetramitacao?idProposicao=643979

${ }^{14}$ Veja o documentário "A Terra é plana":

https://f5.folha.uol.com.br/colunistas/tonygoes/2019/03/documentario-a-terra-e-plana-na-netflix-expoeuma-das-crencas-mais-bizarras-da-atualidade.shtml 
praticam agricultura sustentável, manejo florestal ou manejo de rebanho tem algo a contribuir para a pesquisa científica nessas áreas. Há inclusive uma disciplina interdisciplinar dedicada à explicitação desse conhecimento tradicional, a etnobiologia. Trata-se do estudo do conhecimento e dos conceitos desenvolvidos por uma sociedade sobre o seu ambiente ${ }^{15}$. Como essas populações têm conhecimento prático e de peculiaridades do local que podem ser relevantes para as técnicas de agricultura sustentável ou de manejo florestal de interesse do cientista, pode ser bastante fecunda a participação de membros dessas populações na investigação científica sobre essas técnicas ${ }^{16}$. Também é fundamental incorporá-los no processo de produção do conhecimento se se pretende que as técnicas refinadas cientificamente sejam posteriormente adotadas por essas populações. A perspectiva aqui é a de integração entre conhecimento tradicional e conhecimento científico.

O outro tipo de situação é aquela em que já se antecipa que o conhecimento científico em questão será usado para a formulação de políticas públicas. Neste caso, representantes das populações que serão afetadas por essas políticas públicas poderão ser chamados para participar do processo de produção do conhecimento científico para alimentar os cientistas com valores que desempenharão um papel relevante na avaliação da incerteza. A participação da sociedade civil não é na qualidade de cientista ou investigador, mas como parte afetada pelo conhecimento a ser aplicado. Em muitas situações, o(a) cientista precisa ponderar se a evidência disponível é suficiente para a hipótese que servirá de base para uma política pública. Ele(a) precisa então extrair as prováveis consequências dessa política pública e ponderar se elas são compensadas pela evidência disponível. Uma consequência muito indesejável é uma que se espera que seja

\footnotetext{
${ }^{15}$ Para quem se interessar, a etnobiologia ou etnociência tem repercussões interessantes na reflexão sobre o ensino da ciência. Veja Costa, Ronaldo G. A. "Os saberes populares da etnociência no ensino das ciências naturais: uma proposta didática para aprendizagem significativa”. Revista Didática Sistêmica, v.8, 2008. Disponível em: https://periodicos.furg.br/redsis/article/view/1303

${ }^{16}$ Para uma discussão mais detalhada desse assunto, veja o artigo do filósofo da biologia Charbel El-Hani, professor da UFBA, "Philosophy of Ethnobiology: Understanding Knowledge Integration and Its Limitations", disponível em: https://bioone.org/journals/journal-of-ethnobiology/volume-40/issue-1/02780771-40.1.3/Philosophy-of-Ethnobiology-Understanding-Knowledge-Integration-and-ItsLimitations/10.2993/0278-0771-40.1.3.full
} 
improvável e para a qual se espera ter forte evidência de que seja improvável. No entanto, idealmente não cabe ao cientista avaliar se uma consequência é indesejável e o quão indesejável ela é a partir dos seus valores. É melhor que ele seja auxiliado pela avaliação das pessoas que serão afetadas por essa política pública. Melhor ainda se essa discussão for pública e transparente, tornando explícito os valores que estão pautando a avaliação da incerteza e dos riscos.

A experiência internacional que se tem visto nas últimas décadas, em diversos países, é a organização de painéis de discussão envolvendo tanto especialistas quanto representantes da população civil. Numa primeira rodada, os representantes da sociedade civil são informados pelos especialistas do conhecimento científico relevante e das possíveis consequências da política pública proposta com base nesse conhecimento. Num segundo momento, os representantes da sociedade civil, que, por virem de diferentes setores da sociedade, podem não ter exatamente os mesmos valores, são convidados a discutir e a negociar uma solução compromissada acerca de como avaliar as consequências da política pública. Essa avaliação alimenta os cientistas que podem então ponderar melhor se a evidência de que dispõem apoia bem a política pública em questão. Um resultado interessante dessas experiências é que as pessoas envolvidas confiam e se comprometem mais com a política pública de cuja construção participaram, de certo modo. Claro que pode ser bem mais simples organizar esses painéis no âmbito local de um distrito ou de uma prefeitura, e bem mais complexo no âmbito nacional e mundial.

Desnecessário dizer também que esses espaços de participação na produção do conhecimento científico precisam ser de alguma forma institucionalizados. Uma pergunta que também não podemos deixar de fazer é se a sociedade civil realmente quer se ocupar disso.

\section{Em trabalhos recentes, no interior da epistemologia normativa, você desenvolveu} pesquisas acerca da ética da crença ${ }^{17}$, ou como a conduta doxástica se relaciona com a ética. Tendo em vista a complexidade dessa investigação (tanto pelos

\footnotetext{
${ }^{17}$ Por exemplo, o artigo "A ética da crença: uma defesa moderada da posição indiciária". REVISTA SOFIA (ISSN 2317-2339), Vitória (ES), V.7, N.1, P. 17-40, jan./jun. 2018. Disponível em: https://periodicos.ufes.br/sofia/issue/view/908.
} 
| Entrevista | Eros Carvalho: diálogos interdisciplinares urgentes | Eros Moreira de Carvalho |

| Christiane C. de M. Fernandes | Deborah M. Guimarães | Taciane A. da Silva | Fábio C. dos Santos |

desdobramentos possíveis quanto por sua transversalidade), cabe esclarecer que a nossa questão se situa em um plano amplo, talvez até um pouco genérico, uma vez que não daria conta de abarcar a complexidade do assunto aqui discutido. Assim, gostaríamos de saber de que modo essa investigação pode iluminar nossa compreensão sobre o fenômeno da "pós-verdade", especificamente do movimento anticientificista? E, ainda nesse contexto, como estipular o limiar de evidência suficiente para a crença?

No ano de 2016, "pós-verdade" ("post-truth", em inglês) foi eleita a palavra do ano pelo dicionário de Oxford ${ }^{18}$. Há ocorrências da palavra anteriores a 2016, mas é neste ano, com a eleição de Trump, que seu uso explode na mídia e na academia em narrativas e explicações sobre o que ocorreu na eleição americana. A definição dada pelo referido dicionário é a seguinte: algo "que se relaciona a ou refere a circunstâncias em que fatos objetivos são menos influentes em informar a opinião pública do que apelos à emoção e à crença pessoal". Alguns analistas sugerem que entramos em um novo estágio degenerado, diga-se de passagem - da democracia em que as normas de veracidade não prevalecem mais. O espaço público de discussão, que é crucial para a qualidade da democracia, passa, alega-se, por uma disfunção epistêmica sem precedentes. Tenho algo a dizer sobre essa alegação mais forte, a de que algo novo e sem precedente está corroendo a democracia mundo afora. Antes disso, vou fazer alguns comentários sobre como o alegado fenômeno se conecta à discussão sobre a ética da crença.

O debate sobre a ética da crença diz respeito às normas da crença. William Clifford, no famoso ensaio "A Ética da Crença", chamou a atenção para o fato de que as nossas crenças raramente são privadas, se é que alguma seja, pois elas servem de base para cursos de ações que afetarão outras pessoas. Não temos como isolar as nossas crenças. Quem, durante a pandemia, não usa máscaras porque, sem a devida investigação, acredita que elas são ineficazes vai acabar prejudicando outras pessoas. Sendo a crença então praticamente um bem comum, temos o dever de crer com base em indícios sólidos. A crença que não foi precedida de investigação adequada seria, assim, ilegítima. Ela exibiria negligência ou falta de consideração pelo outro. De fato, zelamos pelo outro em parte zelando pelas nossas crenças. Clifford desfaz uma confusão que vemos

\footnotetext{
${ }^{18}$ Veja a notícia em: https://languages.oup.com/word-of-the-year/2016/
} 
frequentemente na boca das pessoas quando dizem que são livres para crer no que quiserem e que ninguém tem nada a ver com isso. Não, não são. As pessoas são ou deveriam ser livres para formar as suas opiniões sem coerção. Mas desse respeito à autonomia não se segue que elas podem formar a crença de qualquer maneira. A exigência de que se considere a evidência não é uma coerção, mas o que possibilita, na verdade, que a pessoa seja racionalmente autônoma.

Clifford teceu também alguns comentários sobre a credulidade que vão ao encontro do que foi dito acima sobre o fenômeno da pós-verdade. Diante da objeção de que nem toda crença serve de base para cursos de ações que poderão prejudicar terceiros -suponha, por exemplo, a mera crença na existência de uma deidade, desvinculada de qualquer conteúdo moral -, Clifford respondeu que não há tal coisa, pois o "perigo para a sociedade não é meramente o de acreditar em coisas erradas..., mas o de se tornar crédula e perder o hábito de testar as coisas e de as investigar" ${ }^{\prime 19}$. Assim, o problema de relaxarmos numa crença em particular é que isso acaba fomentando a credulidade individual e, por conseguinte, a social. As consequências não param por aí, elas invadem também a esfera pública de discussão. Passamos a nos preocupar menos em dizer a verdade quando o nosso interlocutor não respeita, ele mesmo, a verdade. Da credulidade social podemos passar para a bobagem generalizada, que é caracterizada pela despreocupação ou descaso com a verdade. Aquele que fala bobagem quer nos enganar apenas em relação a sua preocupação ou interesse pelo assunto acerca do qual fala bobagem, mas não está preocupado se o que diz é verdadeiro ou falso. Neste sentido, a bobagem não se confunde com a mentira. O filósofo Harry Frankfurt assinalou que a bobagem, enquanto um sintoma do descaso pela verdade, é mais grave que a mentira na corrosão da norma da veracidade ${ }^{20}$. A mentira ainda é refém da verdade, mas não a bobagem. A difusão da bobagem mina a diferença entre entender as coisas de forma errada e de forma certa. Assim, o relaxamento em relação aos nossos deveres doxásticos deteriora o espaço público de discussão em uma direção muito preocupante, justamente aquela apontada por quem afirma que estamos entrando na era da pós-verdade.

\footnotetext{
${ }^{19}$ Cf. CLIFFORD, William. "A Ética da Crença". In: MURCHO, Desidério (org.). A Ética da Crença. Lisboa: Bizâncio, 2010, p. 97-136.

${ }^{20}$ Cf. FRANKFURT, Harry. Sobre falar merda. Rio de Janeiro: Editora Intrínseca, 2005.
} 
Agora, penso que seria um erro pensar que os populismos que temos visto mundo afora, inclusive no Brasil, sejam o efeito da deterioração do espaço público de discussão no sentido que acabo de mencionar. $\mathrm{Na}$ verdade, os vícios epistêmicos que temos visto neste espaço não se resumem ao descaso com a verdade. Quem fabrica a desinformação sobre kit gay e mamadeira de piroca ou quem nega a existência da pandemia ou a sua gravidade não está provavelmente a falar bobagens, mas mentindo. Aqui é preciso distinguir produtores de consumidores de desinformação. Estou me referindo aos produtores que em muitos casos fabricam desinformação e propaganda como parte de uma estratégia para manipular a opinião pública. A inundação do espaço público com desinformação pode não anular o interesse pela distinção entre entender as coisas de forma errada e de forma certa, mas mina e abala a nossa capacidade de distinguir uma coisa da outra. Pessoas sinceras e investigativas podem ficar em muitos casos com dúvidas legítimas sobre no que acreditar. Note o paralelo com o caso da indústria do tabaco $^{21}$. Por décadas, conseguiram inundar a opinião pública com desinformação e dúvidas sobre a correlação entre fumo e câncer de pulmão, prejudicando milhares de pessoas. Dúvidas têm tanto impacto sobre a ação quanto crenças e por isso mesmo são objeto de manipulação. Tendo a discordar, portanto, da alegação do Frankfurt de que a bobagem é pior que a mentira. Os danos da mentira para uma população que se deixa manipular podem ser tão ou mais graves que os danos que sofrerão se perderem o interesse pela verdade. Tampouco me parece que as democracias estão se enfraquecendo apenas como resultado da perda desse interesse. Uma agenda populista e autoritária, como parece ser a de Trump e a de Bolsonaro, tem todo o interesse em tornar o espaço público de discussão disfuncional, de diferentes maneiras. As estratégias de manipulação e propaganda são antigas, o que há de novo são meios que permitem a sua produção e difusão aceleradas.

Em relação ao movimento anticientificista, não me parece que haja uma única causa ou fator para explicá-lo. Novamente, não creio que ele possa ser explicado apenas pela baixa adesão à norma da veracidade, embora em alguns casos isso possa ser verdade. Mas esse não parece ser o caso de pais investigativos e sinceramente preocupados com o bem-estar dos seus filhos e que, no entanto, desconfiam da segurança da vacina contra

${ }^{21}$ Cf. ORESTES, Naomi \& CONWAY, Erik. Merchants of Doubt: How a Handful of Scientists Obscured the Truth on Issues from Tobacco Smoke to Global Warming. Bloomsbury Press, 2010. 
sarampo. De acordo com Robert Merton, o anticientificismo é, na verdade, esperado dado o próprio ethos da ciência, que se estrutura fortemente em torno de um certo conjunto de valores que pode entrar e entra em tensão com valores de outras instituições da sociedade $^{22}$. Os valores que ele menciona são: universalismo - a ciência não é nacional, não há uma física com contornos da cultura alemã ou brasileira, apenas a ciência física , comunismo - o conhecimento científico é um bem comum, deve ser público -, desinteresse - a ciência não deve estar a serviço de uma ideologia - e ceticismo organizado - nada é imune à investigação, não há dogmas na ciência. Claro que se trata de valores com funções regulativas e a ciência real, social e historicamente situada, aproxima-se mais ou menos desses valores. Não é então difícil ver as tensões que podem surgir entre ciência e sociedade. $\mathrm{O}$ valor do comunismo entra em choque com interesses corporativos que preferem que certos resultados científicos, especialmente aqueles necessários para a produção de produtos comercializáveis, possam ficar em segredo. $\mathrm{O}$ valor do desinteresse entra em choque com certas políticas de governo, como, por exemplo, exigir que cientistas digam que um certo medicamento é confiável, pois isso vai ao encontro de uma política do governo. O valor do universalismo entra em choque com projetos fortemente nacionalistas que querem dar contornos nacionais à ciência. $\mathrm{O}$ ceticismo organizado entra em choque com quaisquer outras instituições que se estruturam em torno de dogmas. O conflito entre ciência e religião surge daí. Não é à toa que o anticientificismo encontra terreno fértil no Brasil. Embora haja um sentido em que se possa dizer que almejamos uma sociedade laica, a nossa Constituição expressa isso embora eu tenha cada vez mais dúvidas de que isso seja suficiente para dizer que ainda temos esse projeto -, o fato é que nós, brasileiros, jamais fomos laicos. Uma sociedade que pensa que a crença em Deus é fundamental para a posse de valores morais ${ }^{23}$ não pode ser considerada laica. Por fim, Merton salienta que os maus usos da ciência também acabam depondo contra ela e são um mobile forte para sentimentos anticientificistas. Isso explica por que, por exemplo, a ciência encontra resistência em certos setores da

${ }^{22}$ Cf. MERTON, Robert. Ensaios de Sociologia da Ciência. São Paulo: Editora 34, 2012.

${ }^{23}$ Segundo uma pesquisa de 2019, essa crença é mais arraigada no Brasil do que, por exemplo, na Turquia, e equiparável à África do Sul. No Brasil, $84 \%$ da população acredita nesta associação. Na Argentina, $55 \%$. Perdemos apenas para a Nigéria, Quênia, as Filipinas e a Indonésia. Veja a pesquisa "The Global God Divide", disponível em: https://www.pewresearch.org/global/2020/07/20/the-global-god-divide/ 
esquerda. $\mathrm{O}$ fato é que a ciência foi instrumentalizada para apoiar o neocolonialismo que assistimos nos séculos XIX e XX. É natural que isto tenha despertado muitas desconfianças que se sedimentam em atitudes e às vezes até em movimentos anticientificistas. No momento atual, creio que o universalismo, mas sobretudo o desinteresse, são vistos como ameaças a certas agendas políticas e por isso mesmo a mobilização anticientificista, não só no Brasil, mas em várias partes do mundo. Acho importante salientar esses pontos pois um esforço educacional para melhorar o espírito crítico da população em geral e arraigar a norma da veracidade, embora crucial e necessário, não vai por si só eliminar as tensões entre ciência e sociedade.

5. Acompanhando as suas publicações e a sua atuação acadêmica, temos visto que um conceito bastante relevante às pesquisas que permeiam a interdisciplinaridade entre epistemologia e fenomenologia é a noção de affordance, termo originalmente proposto por James Gibson para designar "algo que se refere tanto ao ambiente quanto ao animal" (p. 15). Conforme o seu artigo Sintonizando com o mundo: uma abordagem ecológica das habilidades sensoriomotoras, ${ }^{24}$ o mundo é estruturado por affordances (p. 5), possibilidades de ação com valência positiva ou negativa. Há uma passagem em seu artigo que você expõe um dado fenomenológico relativo às affordances: 0 fato de estarmos abertos também às suas solicitações. ${ }^{25}$ Uma vez que a compreensão acerca dessas solicitações não é suficiente para explicar a origem da motivação às ações, gostaríamos de saber se poderíamos interpretar as affordances, pelo viés fenomenológico, como uma forma pré-compreensiva capaz de normatizar as relações entre os seres humanos e os estímulos que lhes advêm do ambientemundo circundante, dado que elas conferem significatividade ao organismo (p. 15).

${ }^{24}$ Cf. CARVALHO, Eros. Sintonizando com o mundo: uma abordagem ecológica das habilidades sensoriomotoras. In: Giovanni Rolla \& Gerson Araújo Neto (eds.). Ciência e conhecimento.

${ }^{25} \mathrm{Cf}$. "O dado fenomenológico é que não só estamos abertos às affordances dos objetos circundantes, mas também às suas solicitações. Isto é, algumas das possibilidades de ações disponíveis, em função de nossas necessidades e planos, nos solicitam agir (...). A compreensão explícita e articulada de uma solicitação não é suficiente para explicar como nos motivamos a agir. Esta é uma consideração importante acerca das habilidades corporais e do modo como o mundo nos é revelado através do exercício das mesmas (...)" (Idem, p. 6). 
| Entrevista | Eros Carvalho: diálogos interdisciplinares urgentes | Eros Moreira de Carvalho |

| Christiane C. de M. Fernandes | Deborah M. Guimarães | Taciane A. da Silva | Fábio C. dos Santos |

\section{Seria possível estabelecer graduações desse suposto aspecto normativo da affordance conforme a sua ocorrência em animais e em seres humanos.}

Antes de entrar na discussão mais complicada sobre o aspecto normativo das affordances, gostaria de fazer um esclarecimento. Como bem formulado na questão, algumas das possibilidades de ações, em função dos nossos interesses e projetos, são mais salientes do que outras e por isso solicitam a ação. Se estou com fome, uma maçã solicita a ação de me nutrir, mas se estou num modo mais descontraído, a maçã pode solicitar a ação de brincar, jogando-a para cima e apanhando-a em seguida. Nesse sentido, as solicitações, situadas nos devidos contextos, são suficientes para explicar algumas ações. Mas isso só é inteligível a partir do meu engajamento prático. Quando afirmei que "a compreensão explícita e articulada de uma solicitação não é suficiente para explicar como nos motivamos a agir", tinha em mente uma forma de intelectualismo que sustenta que só atitudes proposicionais, como crenças e desejos, podem explicar a ação. Creio que esse intelectualismo também foi alvo de crítica do Merleau-Ponty. Essa é uma posição que eu rejeito e contra a qual a psicologia ecológica provê boas razões também. As possibilidades de ações que percebemos diretamente e que nos solicitam a agir são razões para agir ainda que não sejam atitudes proposicionais. De modo semelhante, há muitas coisas que fazemos por hábito. Ao acordar, invariavelmente, me dirijo para a cozinha e começo a fazer o meu café. Posso estar a pensar em várias coisas, planejando o que farei na manhã, tentando lembrar de um sonho etc., enquanto faço habitualmente o meu café. O fato de não pensar ou ter pensamentos sobre como fazer o café não torna o fazer café algo menos que uma ação minha. E se alguém me perguntasse por que estou fazendo café, a resposta “por que eu sempre faço café ao acordar" seria suficiente e perfeitamente inteligível. Hábitos e percepções podem explicar ações tanto quanto crenças e desejos. Podemos chamar a inteligibilidade do mundo que nos é oferecida pela percepção e pelos hábitos de "pré-compreensão" e, nesse sentido, concordo com vocês que a percepção de affordances é uma forma de pré-compreensão. Mas eu prefiro dizer que se trata de uma compreensão prática em oposição a uma compreensão teórica e proposicional. Por que penso que enfatizar que se trata de uma forma de compreensão genuína não é um movimento meramente verbal? Porque quando agimos por hábito ou somos guiados pelo que percebemos não estamos meramente reagindo, não se trata de um reflexo automático, mas 
de uma ação intencional e flexível que é fruto do nosso engajamento prático com o mundo. Não vejo razão para negar o atributo de compreensivo em toda a sua extensão à inteligibilidade do mundo que o engajamento prático nos oferece.

Tal como inicialmente formulada por Gibson, a abordagem ecológica da percepção enfatiza mais semelhanças que diferenças entre a percepção humana e a nãohumana. Como as affordances são, em princípio, relações diádicas entre o ambiente e o organismo, o ambiente oferece oportunidades de ação não só para humanos, mas para qualquer organismo vivo. Quais affordances? Vai depender das habilidades que o organismo possui. Uma superfície plana e rígida oferece a oportunidade de locomoção não só para nós, mas para gatos, cachorros, lebres e todo tipo de animal capaz de locomoção. A superfície de um lago não oferece a oportunidade de locomoção para nenhum desses animais, mas oferece para mosquitos bem leves. O mundo é, portanto, apresentado como significativo para cada animal em virtude das habilidades que ele possui e do que ele pode fazer no seu ambiente, mais especificamente, no seu nicho. $\mathrm{O}$ nicho nada mais é do que o conjunto de affordances que o ambiente oferece para um animal específico. Como a affordance é relacional, um mesmo ambiente físico pode comportar múltiplos nichos. Nesse sentido, não haveria nenhuma diferença fundamental entre a nossa percepção e a percepção de animais não-humanos. No entanto, segundo Alan Costall $^{26}$ e vários outros defensores da abordagem ecológica, algumas affordances disponíveis para humanos só são adequadamente compreendidas se encaradas como uma relação triádica que envolve o ambiente, o organismo e um conjunto de práticas e convenções sociais. Para tomar um exemplo clássico de Gibson, uma caixa postal oferece a ação de enviar carta para um humano com a habilidade de escrever cartas em uma comunidade com um sistema postal. A caixa postal oferece a oportunidade de enviar cartas apenas em relação a uma comunidade que possui um conjunto de práticas que sustenta um sistema postal. Um indivíduo de uma sociedade sem um sistema postal e que não sabe o que é um sistema postal não perceberia esta oportunidade diante de uma caixa postal. O terceiro elemento da relação triádica, as práticas sociais, é portanto fundamental.

\footnotetext{
${ }^{26}$ C.f. COSTALL, Alan. "Socializing affordances". Theory \& Psychology, v. 5, n. 4, p. 467-481, 1995.
} 
As affordances triádicas são também chamadas de affordances sociais ${ }^{27}$. Para perceber uma affordance social é preciso ser capaz de coordenar com os demais membros da comunidade que sustentam a prática relevante. Este tipo de affordance, que é portanto moldada socialmente, já que os objetos são então investidos de possibilidades de ações em virtude de uma prática social, está aberta apenas para seres sociais. Nesse sentido, haveria uma diferença mais fundamental entre a percepção de animais sociais, como nós, e de animais não-sociais. É discutível se no nosso caso todas as affordances que percebemos são do tipo social, isto é, reguladas por uma normatividade social. Nesse caso, a imersão e a mediação do ambiente social seria um diferencial do nosso modo de engajar com o mundo.

6. No artigo recentemente publicado em coautoria com Giovanni Rolla, $O$ desafio da integração explanatória para o enativismo: escalonamento ascendente ou descendente (Prometheus, 2020, 33, 161-181), vocês argumentam que uma das duas principais características do enativismo, no caso, negativa, é a "rejeição do paradigma representacionalista, segundo o qual todo ato cognitivo requer a manipulação de representações" (p. 162) e que ela "abre caminho para uma concepção de cognição de acordo com a qual o agente está em contato imediato com o seu ambiente" (p. 162). Já a característica afirmativa do enativismo seria a responsável por explicitar o que vincula o agente ao mundo sob esse novo viés anti-representacionalista, por assim dizer, ou seja, "a ação explanatória do agente no seu meio ambiente” (p. 162). Vocês defendem ainda que esse novo viés constitui uma ressonância da tradição fenomenológica de Merleau-Ponty e de Heidegger (p. 163). Diante desse legado do método fenomenológico, gostaríamos de saber se e como a família de teorias do “enativismo" se apropria especificamente das críticas ontológico-hermenêuticas heideggerianas à perspectiva da representação, paradigmática da época moderna, bem como da tese acerca do caráter derivado desta em relação à estrutura originária que descreve a relação homem-mundo, ser-no-mundo (In-der-Welt-sein), não mais sob o paradigma do conhecimento.

\footnotetext{
27 Veja o verbete introdutório sobre o tema: CARVALHO, Eros. "Social Affordance". In: Vonk J., Shackelford T. (eds.) Encyclopedia of Animal Cognition and Behavior. Cham: Springer. Disponível em https://doi.org/10.1007/978-3-319-47829-6 1870-1
} 
Muitos, mas não todos, autores e autoras que se identificam como enativistas ou desenvolvendo abordagens enativistas circulam na e comercializam com a tradição fenomenológica. É o caso do Varela, do Thompson, da de Jaegher, do Gallagher, da Maiese e muitos outro(a)s. No entanto, o projeto principal desses pensadores ou pelo menos de boa parte deles não é desenvolver a tradição fenomenológica, mas rearticular o paradigma ou programa de pesquisa das ciências cognitivas. Na visão deles, o paradigma tradicional das ciências cognitivas, o cognitivismo clássico, que entende a cognição como manipulação computacional de representações, está profundamente equivocado. Eles encontram na tradição fenomenológica várias ideias que buscam incorporar nas suas articulações das concepções de mente e cognição, como, por exemplo, a distinção entre corpo físico e corpo vivido, e também, como salientado na pergunta, críticas a certas concepções da mente que nos acompanham desde a modernidade e que se encontram presentes no cognitivismo clássico, como a concepção que confere centralidade à noção de representação na vida mental. No entanto, como o foco é a articulação de um programa de pesquisa empírica para as ciências cognitivas, essa inspiração e apropriação da tradição fenomenológica não é algo que aparece através da análise exegética e cuidadosa dos textos da tradição fenomenológica, embora membros dessa tradição sejam recorrentemente mencionados e citados. Essa influência opera mais como um pano de fundo de intuições e ideias que guiam o trabalho articulador dos enativistas e simpatizantes. No clássico The Embodied Mind, de Varela, Thompson e Eleanor Rosch, eles chegam a ser críticos da fenomenologia, afirmam inclusive que o projeto de Husserl estaria comprometido com a centralidade da noção de representação. O Thompson se retrata em um livro ${ }^{28}$ posterior e reconhece que o conhecimento que tinham de Husserl na época em que escreveram o The Embodied Mind era bastante limitado. Faço essas considerações pois a pergunta parece pedir algo muito mais específico do que podemos encontrar nos textos dos enativistas e simpatizantes, o que é esperado, dado o projeto em que se engajaram.

Isso não nos impede, claro, de apontar algumas confluências. Os enativistas reclamam que a definição de cognição centrada na noção de representação deixa de lado

28 C.f. THOMPSON, Evan. A Mente na Vida: Biologia, Fenomenologia e Ciências da Mente. Lisboa: Instituto Piaget, 2013, p. 473-478. 
dimensões essenciais da cognição, como o seu caráter corporificado e situado. Ao contrário, a noção de representação alimenta a concepção da mente como destacada do mundo e independente das contingências sociais e históricas. Raciocínios sobre cenários contrafactuais distantes parecem alimentar essa concepção. Mesmo sem um corpo, teríamos os pensamentos e até as percepções que normalmente temos. Mesmo se transplantado para outro mundo superficialmente semelhante ao nosso, mas profundamente distinto do nosso histórica e socialmente, teríamos os pensamentos e as percepções que normalmente temos. A mente, segundo o cognitivismo clássico, poderia ser caracterizada pelas suas qualidades intrínsecas, independentemente do mundo ao redor. Já apontei, na resposta anterior, que esse não parece ser o caso em relação à percepção de affordances sociais. O representacionalismo tenta reagir a algumas dessas críticas. O externismo de conteúdo, assumido por muitos representacionalistas contemporâneos, bloqueia em parte essas consequências, e por isso mesmo tem sido o último bastião de defesa do representacionalismo na filosofia da mente anglo-saxônica. Mas ele traz outra consequência que pode ser vista como indesejável: a mente não é mais transparente para si mesma. Essa é, contudo, uma tese que muitos daqueles que defendem a mente como destacada gostariam de defender também. A imagem da mente destacada anda junto com a imagem da mente como senhora de si e, por isso mesmo, absolutamente autônoma, pelo menos em princípio. A noção de representação está, portanto, vinculada a outras ideias morais muito centrais e arraigadas na nossa civilização. Como lembra Charles Taylor, criticar a noção de representação significa cedo ou tarde esbarrar na força dessa tradição ${ }^{29}$. O enativismo rejeita ambas as imagens, no lugar, sugere a imagem da mente como indissociável da agência situada e corporificada. Um mundo de sentido é atuado (enacted) pelo agente a partir das habilidades sensoriomotoras que ele adquire, as quais são uma função tanto do seu corpo vivido quanto do seu histórico de interações com o meio sociocultural. No lugar da autonomia absoluta, temos uma autonomia precária e relacional, as possibilidades de ação disponíveis para o agente emergem e são limitadas pelo seu histórico de vivências e o meio material e sociocultural que encontra. Essas críticas ao representacionalismo encontram forte eco na tradição fenomenológica, e não há dúvida de que, no atacado, os enativistas se alimentaram e continuam se alimentando

${ }^{29}$ C.f. TAYLOR, Charles. "Superar a epistemologia". In: Argumentos Filosóficos. São Paulo: Edições Loyola, 2000, p. 13-31. 
delas. Tanto o aspecto corporal, enfatizado por Merleau-Ponty, quanto o aspecto intersubjetivo, enfatizado por Heidegger, da subjetividade são traços da mente que as ciências cognitivas devem buscar acomodar e explicar. Reitero, no entanto, a diferença de fundo entre os projetos da tradição fenomenológica e do enativismo. Enquanto na tradição fenomenológica a corporeidade e a intersubjetividade são alcançadas e tematizadas a partir de uma reflexão sobre as condições de possibilidade da intencionalidade, no projeto naturalista-enativista, elas são nuançadas e explicadas a partir de estudos empíricos e uma teoria acerca da vida.

Ainda sobre a noção de representação, encontramos enativistas, como o Hutto e o $\operatorname{Myin}^{30}$, que são críticos da noção de representação não tanto por ela ser um sintoma de uma imagem equivocada da mente, embora isso não esteja descartado, mas sobretudo porque os projetos de naturalização da noção de representação, na avaliação deles, fracassaram. Essa é uma crítica da noção de representação que me parece mais alheia à crítica que encontramos na tradição fenomenológica, pois trata-se de uma crítica interna, feita a partir do próprio projeto naturalista.

\section{Ainda segundo o que você e Giovanni Rolla argumentam no artigo $O$ desafio da} integração explanatória para o enativismo: escalonamento ascendente ou descendente, os enativistas radicais explicam performances de cognição superior, pensamentos contrafactuais, inferências, manipulação de símbolos com conteúdo semântico determinado, que aparentemente implicariam estruturas representacionais, mediante uma das descobertas fundamentais da fenomenologia: a intencionalidade (p. 166). Por isso, gostaríamos de saber qual o sentido apresentado por esse fenômeno na perspectiva enativista e se essa significação é ou não similar àquela com a qual opera Edmund Husserl, nas Investigações lógicas, por exemplo.

Entender uma das teses centrais do enativismo, a saber, a continuidade entre a vida e a mente, nos ajudará a entender como o fenômeno da intencionalidade emerge, para os enativistas, no seio da vida. Vou retomar então algumas coisas que eu escrevi na terceira seção do artigo mencionado. O conceito central para entender a vida é o de

\footnotetext{
${ }^{30}$ C.f. HUTTO, Daniel \& MYIN, Erik. Radicalizing Enactivism: basic minds without content. The MIT
} Press, 2013. 
sistema autônomo. Um sistema autônomo é um sistema operacionalmente fechado, composto por vários processos interdependentes entre si que ativamente geram e sustentam uma identidade sob condições de precariedade. Os sistemas autônomos se autoproduzem e se autodistinguem. Eles se autoproduzem porque geram os processos que são necessários para a manutenção dos seus próprios processos. Há uma causalidade circular envolvida na manutenção da vida. Eles se autodistinguem pois formam um sistema operacionalmente fechado que se distingue do ambiente. Os processos metabólicos que dão sustentação à vida celular formam um sistema desse tipo: "uma rede de processos biológicos organizados de tal maneira que a operação desses processos sustenta e regenera a rede de relações e forma uma unidade topológica que se autodistingue no espaço"31. Isso é a autopoiese, uma espécie de sistema autônomo caracterizado no âmbito metabólico. O sistema imunológico e o sistema nervoso também são sistemas autônomos, caracterizados em diferentes níveis. A própria sociedade, caracterizada no nível adequado, pode ser vista também como um sistema autônomo. Outras duas características importantes dos sistemas autônomos são a adaptabilidade e a produção de sentido. A adaptabilidade é a capacidade de um sistema autônomo de regular os seus estados para que os seus processos se mantenham nos limites da sua viabilidade, e produção de sentido é a atividade adaptativa por meio da qual o sistema autônomo regula os seus estados e a sua relação com o ambiente para a preservação da sua identidade. É através dessa atividade que o organismo ou sistema autônomo distingue o que é bom e o que é ruim para a sua autoprodução e autodistinção. Um certo tipo de bactéria, por exemplo, é capaz de mover-se em direção a um meio onde há uma concentração maior de substâncias que são vitais para a sua manutenção, ela assim regula de modo adaptativo a sua interação com o ambiente. Pela atividade de produção de sentido, tais substâncias são percebidas como significativas pela bactéria, por exemplo, como oferecendo nutrição. Segundo Thompson, a atividade de produção de sentido "é reminiscente da noção fenomenológica de intencionalidade" ${ }^{32}$, uma atividade que é direcionada ao mundo para a satisfação das suas necessidades vitais. A atividade de

\footnotetext{
${ }^{31}$ C.f. DI PAOLO, Ezequiel; CUFFARI, Elena; de JAEGHER, Hanne. Linguistic Bodies: the continuity between life and language. The MIT Press, 2018, p. 329

32 C.f. THOMPSON, Evan. Life and mind: From autopoiesis to neurophenomenology. A tribute to Francisco Varela. Phenomenology and the Cognitive Sciences, v. 3, n. 4, 2004, p. 381-398.
} 
produção de sentido é o que confere uma perspectiva ou uma subjetividade ao organismo ou sistema autônomo. O mundo é estruturado e apresentado pela atividade de produção de sentido como sendo significativo, como tendo valência. Assim, pode-se dizer que a intencionalidade emerge da atividade de produção de sentido, trata-se de uma relação emergente que pertence ao sistema autônomo interagindo com o seu ambiente, e é algo que até uma bactéria exibe ao visar certa porção do mundo como oferecendo nutrição. Pelo que foi exposto, creio que haja sim semelhanças, e uma forte inspiração, com o modo como Husserl entendeu a noção de intencionalidade, "a propriedade dos vividos de 'ser consciência de algo" "33.

8. A pandemia, após quase um ano de irrupção, e diferentemente da aposta apressada e ingênua de alguns "especialistas", não ressignificou o pensamento econômico dominante e tampouco mudou o teor das relações humanas dele resultante, mantendo e, na maioria das vezes, aprofundando as desigualdades sociais mundo afora. Este cenário leva a crer que o neoliberalismo supera outra crise e, mais uma vez, permanece praticamente ileso à medida em que a pobreza cresce exponencialmente no planeta. Diante deste quadro, seria possível afirmar que o capitalismo se tornou irreversível, uma vez que nem mesmo uma ameaça global à humanidade enfraqueceu seu alcance? Ou, polemicamente, que o referido sistema econômico é proveniente de um caráter egoístico presente ao longo da história como desenvolvimento de uma tendência do próprio ser do ser humano, cristalizando-se como tal contra a tese de que o capitalismo não passaria de uma mera contingência histórica? No fundo, e sendo ainda mais direto, haveria ainda alguma esperança para uma humanidade historicamente doente de si mesma?

Apesar da tentação, para não fazer eco ao tom pessimista da pergunta, tenho dois comentários a fazer. O primeiro é o esforço louvável de cooperação que se viu ao longo de 2020 no mundo científico para obter melhores tratamentos e uma vacina contra a Covid-19. Cientistas do mundo inteiro deixaram de lado as pesquisas nas quais estavam imersos para se dedicar à pesquisa sobre o vírus Sars-cov-2 e a enfermidade que ele

${ }^{33}$ C.f. HUSSERL, Edmund. Ideias para uma fenomenologia pura e para uma filosofia fenomenológica. Aparecida: Ideias \& Letras, 2006, p. 190. 
acarreta, a Covid-19. Em tempo recorde, chegamos ao final do ano de 2020 com várias candidatas a boas vacinas, com eficácia significativa. Tudo indica que a pesquisa sobre a vacina não será a mesma depois deste funesto episódio e que o mundo científico está mais bem preparado para pandemias futuras. A má notícia, nesse âmbito, é que o Brasil não participou desse esforço coletivo com todo o seu potencial em virtude dos cortes nos investimentos na pesquisa e na ciência ${ }^{34}$. Houve, é verdade, um tímido edital do CNPq para pesquisas relacionadas ao enfrentamento da Covid-19. Também não podemos deixar de enfatizar que as universidades públicas por todo o país se mobilizaram fortemente nesse enfrentamento. Os institutos públicos de pesquisa, como a Fiocruz e o Butantan, tiveram, estão tendo e terão um papel fundamental na pesquisa para a obtenção e produção da vacina. Meu comentário é que muito mais poderia ter sido feito não fosse o contexto atual de restrição de investimentos na pesquisa e na ciência. A tensão gerada pelo atual governo com a OMS também não ajudou, perdemos provavelmente muitas oportunidades de parcerias internacionais.

Meu segundo comentário diz respeito à afirmação implícita na pergunta de que teríamos uma tendência ou natureza egoísta. Eu tenderia a ler a situação numa direção bem diversa e acho que as considerações que o Merleau-Ponty faz no final da Fenomenologia da Percepção sobre o fenômeno da sedimentação, ao discutir o conceito de liberdade, são iluminadoras. Ele afirma que "precisamos reconhecer uma espécie de sedimentação de nossa vida: uma atitude em relação ao mundo, quando ela foi frequentemente confirmada, é para nós privilegiada" ${ }^{35}$. Essa afirmação introduz uma reflexão que o levará, como o leio, a uma posição intermediária entre determinismo e libertismo vulgares. Nem somos completamente determinados, nem completamente livres. Não somos completamente livres porque as possibilidades de ações que pulsam e nos solicitam a agir encontram-se no repertório de vivências passadas, delimitadas pela nossa situação material e sociocultural. Um sujeito que se recusa a dar informações sob tortura não o faz do nada, ele certamente tem uma causa, vivencia o apoio e a comunhão

34 Veja a seção "Financiamentos Cortados" na matéria "A ciência e a Saúde", disponível em: http://www.diretodaciencia.com/2020/12/23/a-ciencia-e-a-saude-uma-breve-retrospectiva-e-licoes-deum-ano-desastroso/

$\frac{}{35}$ MERLEAU-PONTY, Maurice. A Fenomenologia da Percepção. São Paulo: Martins Fontes, 2006, p. 591. 
dos seus parceiros, pensou previamente na possibilidade dessa situação e se preparou para ela. Sua escolha de resistir não vem de um vazio. Ao mesmo tempo, não somos completamente determinados porque o mundo que encontramos não é completamente constituído, ele encerra ambiguidade e está aberto a novas possibilidades. Há espaço para transcender o que aí encontramos. Eu não diria, então, que o "sistema econômico é proveniente de um caráter egoístico", ao contrário, eu afirmaria que tendências egoísticas foram sedimentadas pelo sistema econômico vigente. Em nossa sociedade, as possibilidades de ação que encontramos desde cedo e que são reforçadas em diversos setores da vida nos levam mais à competição que à cooperação, e acabam assim se sedimentando e reforçando. Ao mesmo tempo, há muitos movimentos sociais pujantes que procuram criar as possibilidades para a vivência da cooperação e da solidariedade. Essas transformações, no entanto, não ocorrem do dia para a noite e não era mesmo de se esperar que o choque produzido pela pandemia fosse por si mesmo suficiente para desbaratar o solo de possibilidades de ações sedimentadas que operam como o nosso horizonte de inteligibilidade. Mas daí não se segue que estejamos aprisionados a uma visão de mundo individualista.

Apesar de toda a propaganda da extrema direita em favor do estado mínimo, acho que há uma consciência cada vez mais ampla de que a desigualdade crescente no mundo é insustentável, mesmo entre liberais. A pandemia está acelerando esse processo. Se nada for feito, é provável que vejamos muitas e intensas tensões sociais. 